\title{
Study of the spectra of asymmetric triazines with growth-stimulating activity
}

\author{
Evgenia Builova ${ }^{1, *}$, Elena Kuznetsova ${ }^{1}$, Lyubov Rolnik ${ }^{1}$, Irek Shaikhullin ${ }^{1}$ and Gulia \\ Aminova $^{1}$ \\ ${ }^{1}$ Ufa State Petroleum Technological University, 450064, Ufa, Russia
}

\begin{abstract}
Derivatives of nitrogen-containing heterocycles, in particular compounds of symmetric and asymmetric triazines, are widely used in agriculture as regulators of plant growth and development. Among the derivatives, the most well-known use of symmetric derivatives, however, they are difficult to biodegrade and accumulate in the soil, and as a result in the plants themselves. Therefore, asymmetric triazines, which are easily decomposed in the environment, are more promising in practical terms. Currently, it is very important to use environmentally friendly plant growth and development regulators that do not contain impurities, so much attention is paid to the identification of synthesized compounds of asymmetric triazines with a substituent in position 5 using UV, IR and Mass spectroscopy.
\end{abstract}

\section{Generalized Introduction}

In agricultural practice, plant growth and development regulators (GDR) are used to increase crop productivity and protect plants from adverse environmental conditions.

Plants produce special substances - phytohormones, which regulate its physiological processes. Phytohormones are synthesized by certain cells of the plant body, the main function of which is the management of growth processes. Some hormones stimulate growth (auxins, cytokinins, gibberellins), others inhibit it (abscisic acid).

To date, a large number of synthesized compounds are known that are not produced by plants, but stimulate its growth. Both natural phytohormones and its synthetic analogues are the regulators of plant growth and development.

A significant advantage of the use of plant growth and development regulators is that GDR is used in small doses; therefore, they do not affect the ecological environment and consumer characteristics of agricultural products.

The main functions of plant growth and development regulators are as follows:

- regulation of dormancy, acceleration or suppression of germination;

- regulation of the absorption of minerals;

- regulation of chemical composition due to biochemical effects;

- the impact on the metabolism of crops, the regulation of metabolism, the acceleration of the ripening process, increased productivity;

\footnotetext{
* Corresponding author: evg-builova@yandex.ru
} 
- increased resistance to pests, diseases due to changes in the growth rate of plant organs;

- increased absorption and transport of herbicides, resistance to the damaging effects of herbicides;

- regulation of flowering, aging;

- regulation of the development of lateral buds, the size of plants and their organs, the number of ovaries, an increase in the number of established fruits;

- induction and acceleration of root formation and propagation of plants.

The mechanism of action of plant growth and development regulators has two directions:

- a quick effect on the membrane system: due to the energy of ATP, the transport of hydrogen ions from the cytoplasm to the cell membrane increases and the softening of the cell membrane accelerates;

- slow effect through the genomic system on protein synthesis, which determines the growth of plant body cells [1-3].

A wide range of substances has been proposed and used as GDR. Of particular interest are nitrogen-containing compounds, namely derivatives of triazines. Symmetric triazines are effective biologically active compounds, but do not meet modern environmental requirements. Symmetric triazines accumulate in the soil and enter the human body through plant and animal food. From the point of view of environmental safety, the most promising are compounds of a number of asymmetric triazines, which are easily biodegradable under natural conditions $[4,5]$.

Earlier, we described the preparation methods, physicochemical properties, and test results of the biological activity of 1,2,4-triazines derivatives. In this work, the spectral characteristics of the studied compounds are given.

\section{Materials and methods}

In [6-9], data on the study of methods for obtaining and studying the physical and chemical properties of a wide range of derivatives of asymmetric triazines with a functional group in position 5 are presented. The resulting compounds were identified using UV, IR and Mass spectra. The physical and chemical characteristics of the resulting compounds are shown in the table.

Table. Physico-chemical characteristics of derivatives of 1,2,4-riazines<smiles>[X]c1nc(C)nnc1C</smiles>

\begin{tabular}{|c|c|c|c|c|c|c|}
\hline $\begin{array}{c}\text { № } \\
\text { соед. }\end{array}$ & $\mathrm{X}$ & $\begin{array}{c}\text { Molecul } \\
\text { ar mass }\end{array}$ & $\begin{array}{c}\text { Melting } \\
\text { point, }{ }^{\circ} \mathrm{C}\end{array}$ & $\begin{array}{c}\text { IR-spectrum, } \\
\mathrm{cm}^{-1}\end{array}$ & $\begin{array}{c}\text { UV } \\
\text { spectrum, } \\
\mathrm{nm}\end{array}$ & $\begin{array}{c}\text { The mass } \\
\text { spectrum, } \\
\mathrm{M} / \mathrm{z}\end{array}$ \\
\hline 1 & $\mathrm{OH}$ & 125 & 196 & $\begin{array}{c}3200,1650, \\
1500,1110\end{array}$ & 226,336 & $\begin{array}{c}125,124,97,5 \\
6,43,41,28\end{array}$ \\
\hline 2 & $\mathrm{HS}$ & 141 & 236 & $\begin{array}{c}2600,1190, \\
1500,650\end{array}$ & 226,318 & $\begin{array}{c}141,140,113, \\
59,44,41,28\end{array}$ \\
\hline 3 & $\mathrm{NH}_{2}$ & 124 & $\begin{array}{c}202 \ldots 203 \\
\text { (разл.) }\end{array}$ & $\begin{array}{c}3300,3270, \\
1500,1350, \\
800\end{array}$ & 230,336 & $\begin{array}{c}124,108,80, \\
41,28\end{array}$ \\
\hline 4 & $\left(\mathrm{CH}_{3}\right)_{2} \mathrm{~N}$ & 152 & 143 & 1500,1358 & 270,295 & $152,108,80$, \\
\hline
\end{tabular}




\begin{tabular}{|c|c|c|c|c|c|c|}
\hline & & & & & & $44,41,28$ \\
\hline 5 & $\left(\mathrm{C}_{2} \mathrm{H}_{5}\right)_{2} \mathrm{~N}$ & 180 & 151 & 1530,1350 & 270,295 & $\begin{array}{c}180,108,80,7 \\
2,41,28\end{array}$ \\
\hline 6 & $\left(\mathrm{C}_{3} \mathrm{H}_{7}\right)_{2} \mathrm{~N}$ & 208 & 158 & $\begin{array}{c}2870,1540 \\
1350\end{array}$ & 270,295 & $\begin{array}{c}208,108,100, \\
80,41,28\end{array}$ \\
\hline 7 & $\left(\mathrm{C}_{4} \mathrm{H}_{9}\right)_{2} \mathrm{~N}$ & 236 & 149 & $\begin{array}{c}2870,1548 \\
1345\end{array}$ & 270,295 & $\begin{array}{c}236,128,108, \\
80,41,28\end{array}$ \\
\hline 8 & $\left(\mathrm{C}_{5} \mathrm{H}_{11}\right)_{2} \mathrm{~N}$ & 264 & 161 & $\begin{array}{c}2870,1540 \\
1348 \\
\end{array}$ & 270,295 & $\begin{array}{c}264,156,108, \\
80,41,28\end{array}$ \\
\hline 9 & $\left(t-\mathrm{C}_{5} \mathrm{H}_{11}\right)_{2} \mathrm{~N}$ & 264 & 172 & $\begin{array}{c}2900,1530,13 \\
80,1340\end{array}$ & 270,295 & $\begin{array}{c}264,156,108, \\
80,41,28\end{array}$ \\
\hline 10 & $\left(\mathrm{C}_{6} \mathrm{H}_{131}\right)_{2} \mathrm{~N}$ & 293 & 169 & 1520,1340 & 270,295 & $\begin{array}{c}293,184,80, \\
41,28\end{array}$ \\
\hline 11 & $\mathrm{C}_{6} \mathrm{H}_{5} \mathrm{COHN}$ & 228 & 112 & $\begin{array}{l}3250,3100, \\
1630,1600\end{array}$ & 258,265 & $\begin{array}{c}228,122,108, \\
106,82,80,41 \\
, 28\end{array}$ \\
\hline 12 & $\mathrm{C}_{3} \mathrm{H}_{7} \mathrm{COHN}$ & 194 & 132 & $\begin{array}{l}3300,3070, \\
1690,1550\end{array}$ & 250,263 & $\begin{array}{c}194,122,108, \\
80,72,41,28\end{array}$ \\
\hline 13 & $\mathrm{NH}_{2} \mathrm{NH}$ & 139 & 147 & $\begin{array}{c}3360,3320 \\
1500\end{array}$ & 260,360 & $\begin{array}{c}139,123,108, \\
80,41,28\end{array}$ \\
\hline
\end{tabular}

\section{Results and discussion}

When considering the UV spectra given, a triazine ring with a functional group in position 5 gives a stable signal with an absorption maximum lying in the range from 242 to $380 \mathrm{~nm}$. There are two absorption bands in the spectrum of amino compounds, with peaks at 230 and $336 \mathrm{~nm}$. Upon transition to the derivatives of 1,2,4-triazinones-5, a shift of the first signal to a shorter wavelength region is observed, with a maximum of 226 and $336 \mathrm{~nm}$. In the transition to 5-mercapto derivatives, intense absorption is observed at 226 and $318 \mathrm{~nm}$.

When studying the IR spectra, it was revealed that the triazine ring has intense absorption bands in the region of $1500 \ldots 1600$ and $700 \ldots 8000 \mathrm{~cm}-1$. The 5 -amino derivative of an asymmetric triazine is characterized by the presence of specific absorption bands at 3300,3270 , and $1350 \mathrm{~cm}-1$.

The oxo derivatives have signals of the carbonyl group at frequencies of 1650 and 1110 $\mathrm{cm}-1$, as well as a signal characteristic of the hydroxy group, $3200 \mathrm{~cm}-1$, which indicates the presence of tautomeric forms for substituted 1,2,4-triazinones-5.

For mercapto derivatives, there are no characteristic intense signals, only weak wide absorption bands are observed at 450 and $650 \mathrm{~cm}-1$ [10 - 12].

The most reliable information on the structure of the studied compounds is given by mass spectra. The mass spectra of the synthesized triazines contain intense molecular peaks that correctly coincide with the calculated molecular weights, which indicates the correspondence of the assumed real structure. With an electron impact, a triazine molecule breaks up into specific fragments. The decay of the molecule is preceded by the localization of the charge at the most electronegative center and the redistribution of electron density with the participation of electrons of the double bond of the triazine ring. An analysis of the presence and intensity of fragments allows one to determine the decay scheme, which fundamentally depends on the structure of the triazine molecule [13].

Characteristic fragments of the decomposition of 1,2,4-triazines without functional groups are $\mathrm{R}^{1}-\mathrm{C} \equiv \mathrm{N}^{+}, \mathrm{R}^{1}-\mathrm{C} \equiv \mathrm{CH}^{+}$и $\mathrm{R}^{2}-\mathrm{C} \equiv \mathrm{N}^{+}$.

The mass spectroscopic behavior of 5-functionally substituted 1,2,4-triazines is characterized by the presence of molecular ion peaks. The main direction of decomposition of these compounds under the influence of electron impact is the removal of substituents at position -5 . Further splitting of heterocyclic ion radicals occurs due to the elimination of the 
nitrogen molecule. The decomposition of a molecule of 3,6-dimethyl-5-amino-1,2,4triazine is shown in scheme 1.

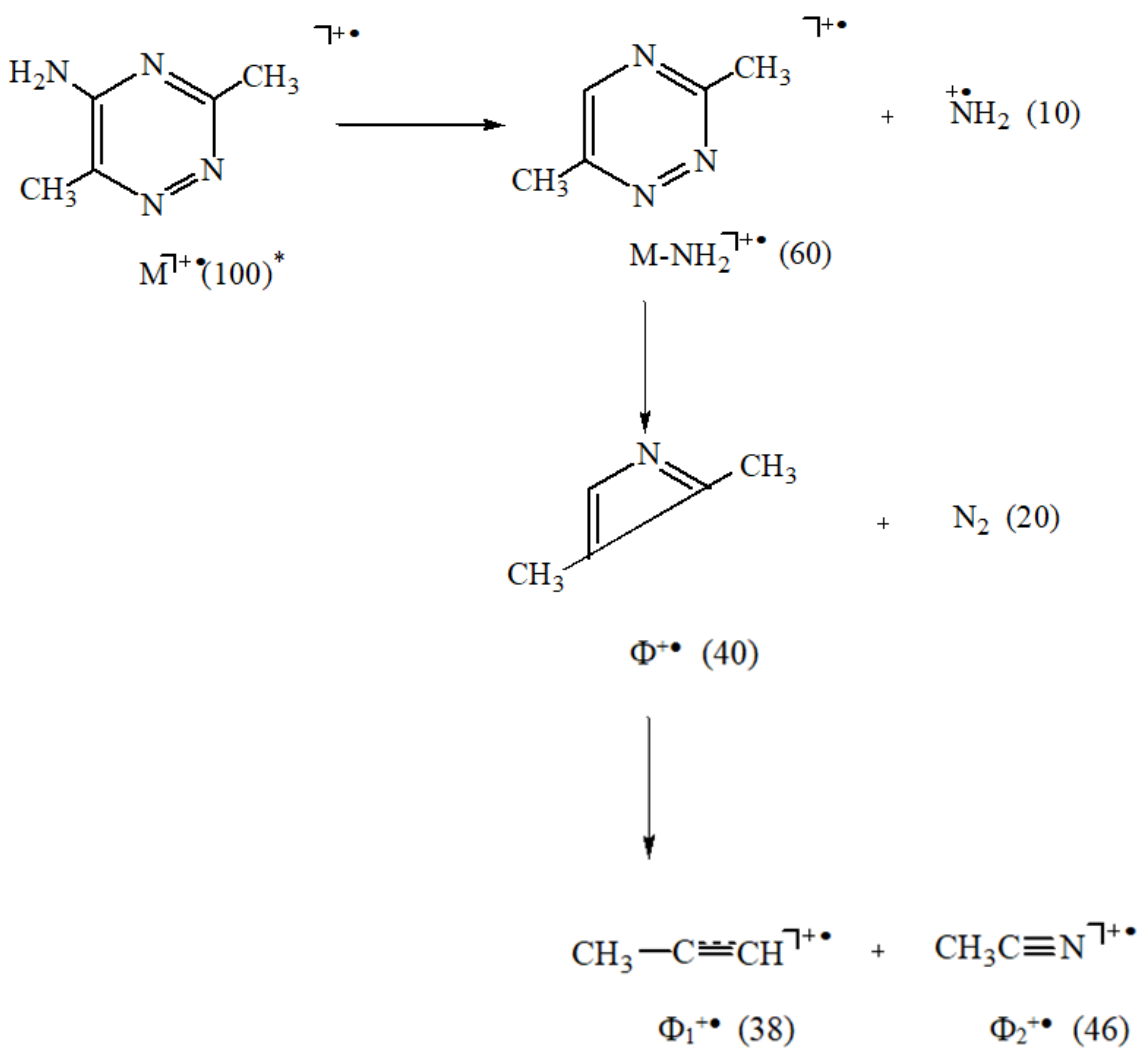

Scheme 1. The decomposition of a molecule of 3,6-dimethyl-5-amino-1,2,4-triazine

In the spectrum of the oxo-derivative asymmetric triazine, along with the $\mathrm{M} \neg+$ peaks, significant peaks $(\mathrm{M}-\mathrm{H}) \neg+$ were also recorded, which suggests the presence of two tautomeric forms. The fragments corresponding to the molecules of nitrile, nitrogen and isocyanate indicate two directions of decay. The decay scheme is shown in Figure 2.

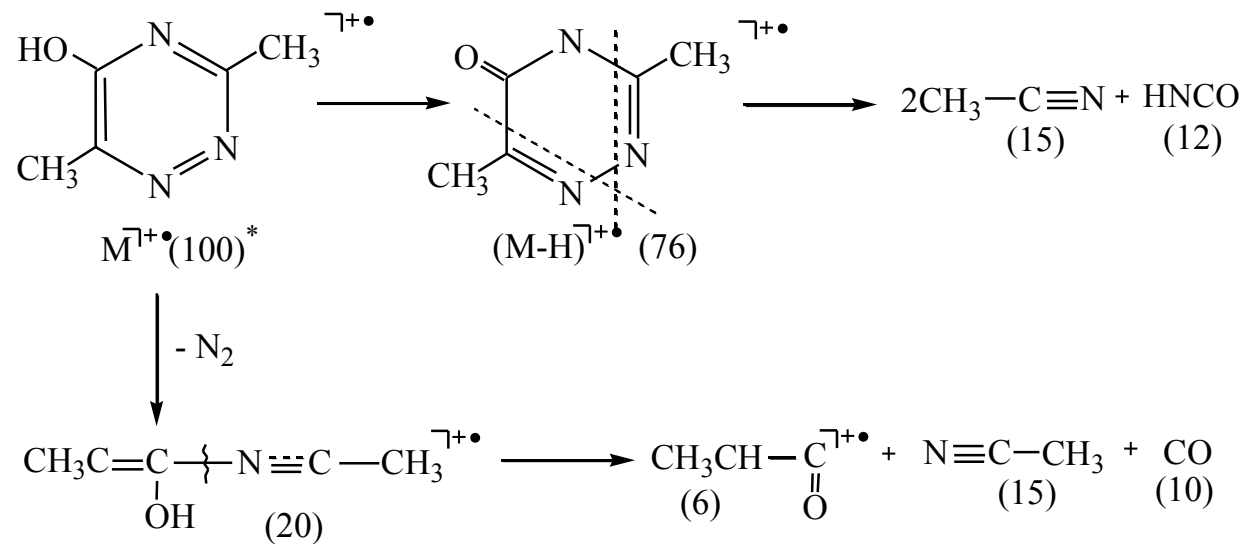

Scheme 2. The decay of the molecule 3,6-dimethyl-1,2,4-triazinone-5 
Fragmentation mainly proceeds through the oxoform.

A similar picture is observed for derivatives of 5-mercapto-1,2,4-triazines. In the spectra of 3,6-dimethyl-5-mercapto-1,2,4-triazine, fragments corresponding to the molecules: nitrile and thiocyanate were fixed, which is due to the presence of two tautomeric forms.

\section{Conclusion}

The obtained IR and UV spectra quite convincingly prove the composition and structure of the studied compounds. In the mass spectra, the peaks corresponding to molecular ions, protonized ions, and fragments that are formed upon cleavage of the hydroxyl, mercapto, and amino groups, as well as the residue of the triazine ring, are most clearly detected in the mass spectra.

\section{References}

1. M.A. Ikrina, A.M. Kolbin, Plant growth and development regulators, Stimulants. 1, 696 (M.: Chemistry, 2004)

2. D.L. Rakhmankulov, G.G. Bazunova, R.S. Musavirov, A.P. Klevtsova, M.S. Kireeva, F.N. Latypova, Modern chemical plant protection products. Regulators of plant growth and development, 1, 196 (Ufa: Reakt Publishing House, 1999)

3. E.M. Movsumzade, R.B. Valitov, G.G. Bazunova, G.K. Aminova, Growth Regulators and Harvest, 208 (Ufa: publishing house "Reagent", 2000)

4. N.N. Melnikov, Yu.A. Baskakov, Chemistry of herbicides and plant growth regulators, 723 (Moscow: Goskhimizdat, 1962)

5. V.S.Sheveluha, Khrustaleva L.I. Blinovsky I.K. Assessing the genetic risk of using plant growth regulators, (M.: Agropromizdat, 1990.

6. A.K. Mazitova, I.A. Sukhareva, G.F. Aminova, D.R. Galieva, Bashkir chemical journal, 14 (2), 25 - 29 (2007)

7. A.K. Mazitova, V.Kh. Khamaev, E.Sh. Ulyamaeva, I.A. Sukhareva, Bashkir chemical journal, 6 (4), 4 - 16 (1999)

8. A.K. Mazitova, E.A. Buylova, G.K. Aminova, Bashkir chemical journal, 13 (2), 5 $11(2006)$

9. V.Kh. Khamaev, V.A. Danilov, R.N. Khannalov, A.K. Mazitova, Journal of Organic Chemistry, 30 (5), 777-781 (1994)

10. L. Bellamy, Infrared spectra of complex molecules, 590 (M .: I.L, 1963)

11. K. Nakanisi, Infrared spectra and the structure of organic compounds, 216 (M .: World, 1965)

12. L.A. Kazitsyna, N.B. Kupletskaya, The use of $U V, I R$ and NMR spectroscopy in organic chemistry (M .: Higher school, 1971)

13. P.B. Terentyev, A.P. Stankevichus, Mass spectrometry of biologically active nitrogen bases (Vilnius: Moxlas, 1977) 